\title{
A Generalized Power System Architecture Sizing and Analysis Framework
}

\author{
David J. Sadey ${ }^{1}$, Jeffrey T. Csank ${ }^{2}$, Patrick A. Hanlon ${ }^{3}$, Ralph H. Jansen ${ }^{4}$ \\ NASA Glenn Research Center, Cleveland, OH, 44135, USA
}

\begin{abstract}
The aeronautics industry has been challenged to increase efficiency, reduce noise and emissions, and decrease dependency on carbon-based fuels. To address these needs, NASA has identified and begun to pursue electrified aircraft as a possible solution. The power system for an electric aircraft can exist in many different forms, however; at the early design stage the engineer(s) must identify whether a hybrid- or turbo- electric solution may be best, whether the power transmission system is to be AC or DC, and to ultimately answer the question: does the electric solution provide a net system benefit compared to the fully mechanical solution? This paper describes a generalized power system architecture sizing and analysis framework to provide a mechanism to answering these questions, along with an example based on the STARC-ABL Architecture.
\end{abstract}

\section{Introduction}

$\mathrm{N}$ ASA is investing in developing advanced aircraft concepts and technologies for the future that will enable reductions in noise, $\mathrm{NO}_{\mathrm{x}}$ emissions, and aircraft fuel burn. ${ }^{1,2}$ These advanced propulsion concepts that are being considered include hybrid-electric, ${ }^{3}$ such as the Boeing-General Electric (GE) "Sugar Volt" hybrid-electric vehicle which combines a GE hybrid fan with Boeing aircraft, and a turbo-electric with a tail cone thruster concept, ${ }^{4}$ known as STARC-ABL, featuring two main engines and an electrically powered aft thruster for boundary layer ingestion. Both the hybrid-electric and turbo-electric concepts rely on a power system to deliver electrical power from an electrical power source, e.g. battery or generator, to a motor which drives a propulsor that provides thrust for the vehicle. Incorporating the power system into these systems, where the power system delivers the electrical power for propulsion, requires the power system to be included in the conceptual design phase of the propulsion system. The power level of the electrical power system impacts the overall weight, thermal system requirements, and efficiency of the propulsion system, and these tradeoffs need to be considered to meet the design objectives.

A tool has been developed in the MATLAB ${ }^{\circledR}$ environment that has the ability to accept the torque and speed requirement(s) of the motor(s) and determine the size of the power system components (such as converters, switchgear, cables, and machines) along with the weight, thermal impact, and losses in the system from the motor to the source. This paper will discuss the current state of the tool, high-level descriptions of the algorithm, an example analysis that the tool has been used for, and future work.

\section{Power System Sizing Framework}

The overall framework of a power system sizing and analysis study should provide several benefits. ${ }^{5}$ The first benefit is the electric aircraft propulsion system performance can be estimated using simplified mass and efficiency models for the power system elements. Second, various components can be compared, allowing better investment selections. Third, the impact of the material-level investments on the machines, power converters, switchgear, and cables can be assessed by estimating the impact to key performance parameters (KPPs) such as specific power and efficiency of the electric drive system and its components. Lastly, sensitivity analysis can be performed to quickly assess the strengths and weaknesses of a design.

In this paper, we propose an extended framework in which parametric analysis can be performed on a given power system architecture and/or its components; the results of the analysis would provide inputs to the benefits described

\footnotetext{
${ }^{1}$ Electrical Engineer, Power Management and Distribution Branch, david.j.sadey@nasa.gov

2 Electrical Engineer, Power Management and Distribution Branch, jeffrey.t.csank@nasa.gov, AIAA Sr. Member

${ }^{3}$ Electrical Engineer, Power Management and Distribution Branch, patrick.a.hanlon@nasa.gov

${ }^{4}$ Technical Management, Aeronautics Directorate, ralph.h.jansen@nasa.gov, AIAA Member.
} 
previously. In addition, various power system architectures, be it hybrid- or turbo-electric, AC or DC transmission, can be compared to help determine the most optimal architecture (mass and/or efficiency) for a given vehicle.

The proposed framework is based on the concept of modular code by using object-oriented programming. Each power system component, e.g. a motor or inverter, is modularized as its own class. Each class contains objects (properties) specific to the component it is describing, allowing for detailed models of the component to be created. For a simplified example, a motor class can be created containing the two KPPs of specific power and efficiency as the objects. The same can be done with the power electronics, cables, generator(s), energy storage, etc. Once the power system component classes are created, the classes can be linked in order from load to source as illustrated in Figure 1. Each class (grey/mechanical or blue/electrical) performs its own relevant calculations based on its object states (yellow, orange, and green) and input data (such as power or voltage) to determine relevant data such as weight and power loss. The relevant electrical output data is then passed to the next linked class to continue the process. Thermal loss (red) is also collected to estimate thermal mass. In the case of this paper, only real and reactive power is passed between classes; although a more complex study is assumed to contain relevant information on voltage, current, power, frequency, and even angular data.

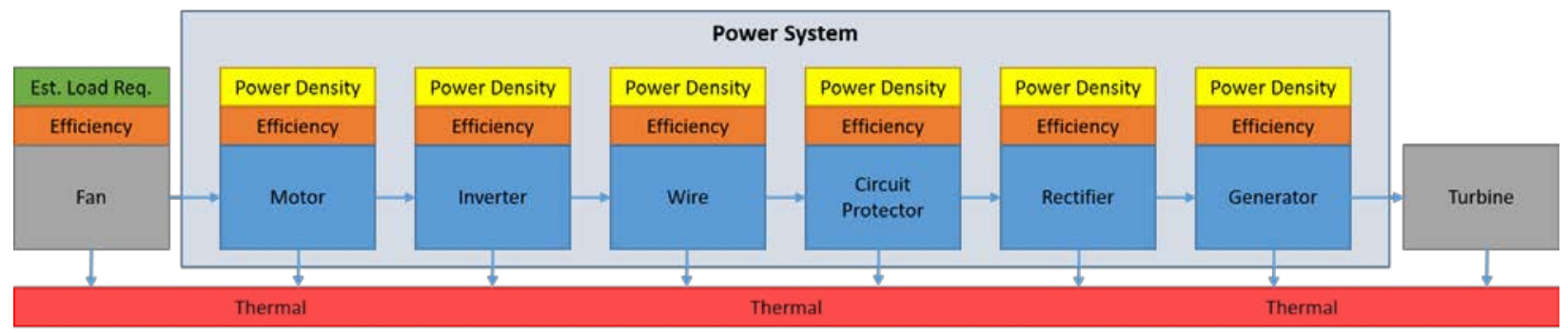

Figure 1: Turbo-Electric based Example for Module Linkage of the Power System Classes

The flexibility of the proposed framework allows for several advantages. First, detailed models and calculations can be performed by domain experts for each class. Second, the modular code can be expanded to include thermal system sizing and analysis in much the same manner. Third, the code is well suited for fast calculations in which system-wide trades can be performed at the power system architecture or component level. Lastly, as shown in Figure 2, the code can be integrated at the vehicle sizing level to help determine the most optimal power system for a given vehicle (projected to be an iterative process).

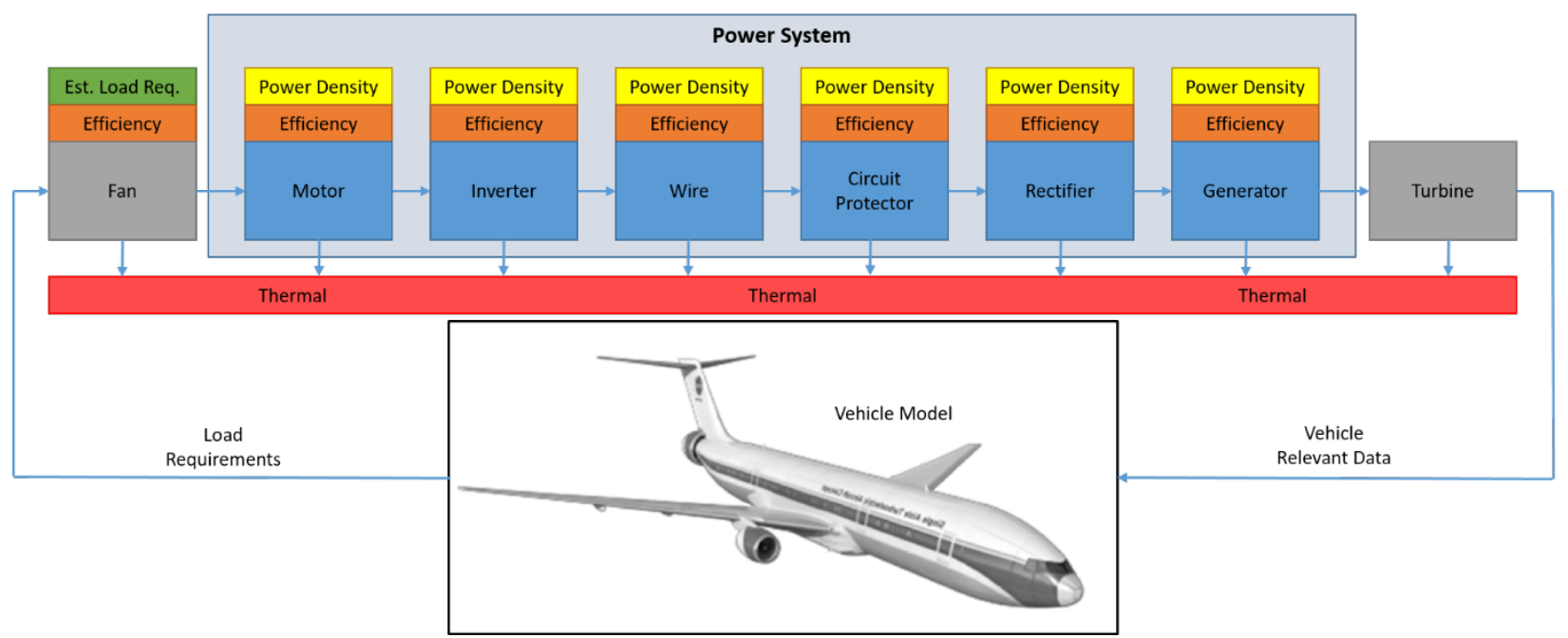

Figure 2: Integrated Code Structure for Vehicle Sizing 


\section{Power System Sizing Component Class Descriptions}

\section{A. Machines (Generator and Motor)}

The machine classes (generators and motors) are currently sized based on KPPs of power density and efficiency. ${ }^{5}$ The KPPs used for this purpose are shown in Table 1. In the case of this paper, apparent power density $(\mathrm{kVA} / \mathrm{kg})$ will be used to size the machine classes as opposed to real power density $(\mathrm{kW} / \mathrm{kg})$. The reason for this is to account for reactive power effects in the sizing and performance of the machines, since some system

Table 1: KPP Metrics of Machine Classes

\begin{tabular}{|c|c|c|}
\cline { 2 - 3 } \multicolumn{1}{c|}{} & $\begin{array}{c}\text { Apparent Power } \\
\text { Density (kVA/kg) }\end{array}$ & $\begin{array}{c}\text { Baseline } \\
\text { Efficiency (\%) }\end{array}$ \\
\hline Motor & 9 & 95 \\
\hline Generator & 9 & 95 \\
\hline
\end{tabular}
architectures may not operate at solely unity power factor. In addition, the real power loss of a machine will also need to be adjusted with changes in power factor. Therefore, for AC power calculations, the baseline efficiency KPP $\eta_{\text {baseline }}$ will be corrected such that

$$
\eta_{\text {corrected }}=1-\frac{1-\eta_{\text {baseline }}}{p f_{\text {load }}^{2}}
$$

where $\eta_{\text {corrected }}$ is the new corrected efficiency, and $p f_{\text {load }}$ is the load power factor. The reason for this simplified assumption is that with a constant real power, machine loss varies in relation to the square of the power factor.

\section{B. Power Electronics (Rectifier and Inverter)}

In the same manner as the machines, the power electronics classes will utilize KPPs of power density $(\mathrm{kVA} / \mathrm{kg})$ and efficiency. For the purposes of this paper, the rectifier and inverter are assumed to be the same device, operating in different quadrants. The metrics for these devices are shown in Table 2.

\section{Cables}

The cable class (module) is composed of two modules: the DC module (2-wire, split-bus) and AC module (3phase). The DC and AC modules are designed to sift through their respective cable lookup tables and procure the most weight-optimal cable satisfying ampacity and voltage drop requirements. The AC Cable class was designed to size AC cables at $400 \mathrm{~Hz}$ and $800 \mathrm{~Hz}$, consistent with operational frequencies aboard aircraft today. The DC cable class accounts for the voltage drop incurred on both lines (a double voltage drop), and the AC and DC classes are assumed to have no neutrals.

The lookup table data for the AC and DC modules within the class were estimated using information from a publication from the Insulated Power Cable Engineers Association (IPCEA). ${ }^{6}$ The table data was estimated based on $2 \mathrm{kV}$ copper marine cable, and provides impedance, weight, and ampacity estimates for DC and AC cables. For simplicity, the DC ampacity of the cable was assumed to be the same as the $60 \mathrm{~Hz}$ ampacity. From there, skin- and proximity-losses and effects at 400 and $800 \mathrm{~Hz}$ were estimated for a triangular configuration with minimum spacing as shown in Table 3.

In some cases, paralleling of cables can increase ampacity while also reducing weight. In this paper, that metric is referred to as the parallel cable limit and is considered within both AC and DC cable sub-modules. The process flow for selecting the optimal cable setup for an AC cable is shown in the flow diagram form in Figure 3. The cable class operates as follows: First, the required aircraft cable metrics (e.g. AC or DC bus, cable length, parallel cable limit, voltage drop tolerance) and all other aircraft component KPPs are initialized. Second, the power sizing tool runs the cable class's preceding component classes and passes calculated load power data into the cable class. The respective AC or DC cable sub-module then calculates and uses the current to evaluate a cable setup that satisfies the current requirement, voltage drop requirement, and parallel cable limit. The method for evaluating the most optimal cable setup is to sequentially loop through the lookup table in Table 3, and compare the loop outcomes to the table cable ampacity and weight. When a cable is found in a loop pass, it is temporarily stored to be compared in later loop passes so that the lightest cable setup is not skipped. When all combinations have been evaluated, the optimal cable parameters are used to calculate significant metrics such as power loss, efficiency, and weight of the cable. The cable class then passes the source power data to the next component, and the power sizing continues. 
Table 3: Weight, Impedance, and Estimated Cable Ampacities

\begin{tabular}{|c|c|c|c|c|c|c|c|c|}
\hline $\begin{array}{c}\text { Size } \\
\text { (AWG/MCM) }\end{array}$ & $\begin{array}{c}\text { Weight } \\
\left.\text { (lbs/10 } 10^{3} \mathrm{ft}\right)\end{array}$ & $\begin{array}{c}\text { Inductive } \\
\text { Reactance } \\
\left(\Omega / 10^{3} \mathrm{ft}\right)\end{array}$ & $\begin{array}{c}\text { AC } \\
\text { Resistance } \\
60 \mathrm{~Hz} \\
\left(\Omega / 10^{3} \mathrm{ft}\right)\end{array}$ & $\begin{array}{c}\text { AC } \\
\text { Resistance } \\
400 \mathrm{~Hz} \\
\left(\Omega / 10^{3} \mathrm{ft}\right)\end{array}$ & $\begin{array}{c}\text { AC } \\
\text { Resistance } \\
800 \mathrm{~Hz} \\
\left(\Omega / 10^{3} \mathrm{ft}\right)\end{array}$ & $\begin{array}{c}\text { DC Current } \\
\text { (A) }\end{array}$ & $\begin{array}{l}400 \mathrm{~Hz} \text { AC } \\
\text { Current } \\
\text { (A) }\end{array}$ & $\begin{array}{c}800 \mathrm{~Hz} \text { AC } \\
\text { Current } \\
\text { (A) }\end{array}$ \\
\hline 18 & 32 & 0.065 & 7.1986 & 7.1986 & 7.1986 & 17 & 17 & 17 \\
\hline 16 & 34 & 0.062 & 4.5132 & 4.5132 & 4.5139 & 25 & 25 & 25 \\
\hline 14 & 44 & 0.057 & 2.8454 & 2.8456 & 2.8465 & 40 & 40 & 40 \\
\hline 12 & 53 & 0.053 & 1.7873 & 1.7879 & 1.7887 & 48 & 48 & 48 \\
\hline 10 & 68 & 0.05 & 1.1281 & 1.1289 & 1.1309 & 62 & 62 & 62 \\
\hline 8 & 96 & 0.048 & 0.6931 & 0.6943 & 0.6973 & 77 & 77 & 77 \\
\hline 6 & 130 & 0.045 & 0.4350 & 0.4367 & 0.4417 & 103 & 103 & 102 \\
\hline 4 & 210 & 0.039 & 0.2942 & 0.2971 & 0.3045 & 137 & 136 & 135 \\
\hline 2 & 314 & 0.037 & 0.1799 & 0.1847 & 0.1967 & 181 & 179 & 173 \\
\hline 1 & 393 & 0.036 & 0.1438 & 0.1495 & 0.1639 & 208 & 204 & 195 \\
\hline $1 / 0$ & 485 & 0.035 & 0.1150 & 0.1224 & 0.1393 & 243 & 236 & 221 \\
\hline $2 / 0$ & 596 & 0.034 & 0.0922 & 0.1014 & 0.1207 & 281 & 268 & 246 \\
\hline $3 / 0$ & 709 & 0.034 & 0.0737 & 0.0853 & 0.1059 & 321 & 299 & 268 \\
\hline $4 / 0$ & 836 & 0.033 & 0.0590 & 0.0735 & 0.0952 & 376 & 337 & 296 \\
\hline 262 & 1015 & 0.034 & 0.0494 & 0.0659 & 0.0870 & 436 & 377 & 328 \\
\hline 313 & 1178 & 0.033 & 0.0413 & 0.0594 & 0.0800 & 487 & 406 & 350 \\
\hline 373 & 1400 & 0.032 & 0.0347 & 0.0539 & 0.0729 & 553 & 443 & 381 \\
\hline 444 & 1654 & 0.031 & 0.0302 & 0.0509 & 0.0686 & 630 & 485 & 418 \\
\hline 535 & 2005 & 0.031 & 0.0258 & 0.0476 & 0.0638 & 709 & 522 & 451 \\
\hline 646 & 2348 & 0.031 & 0.0221 & 0.0437 & 0.0584 & 783 & 557 & 482 \\
\hline 777 & 2709 & 0.03 & 0.0192 & 0.0394 & 0.0526 & 881 & 614 & 532 \\
\hline 1111 & 3965 & 0.03 & 0.0133 & 0.0328 & 0.0435 & 1098 & 698 & 606 \\
\hline
\end{tabular}




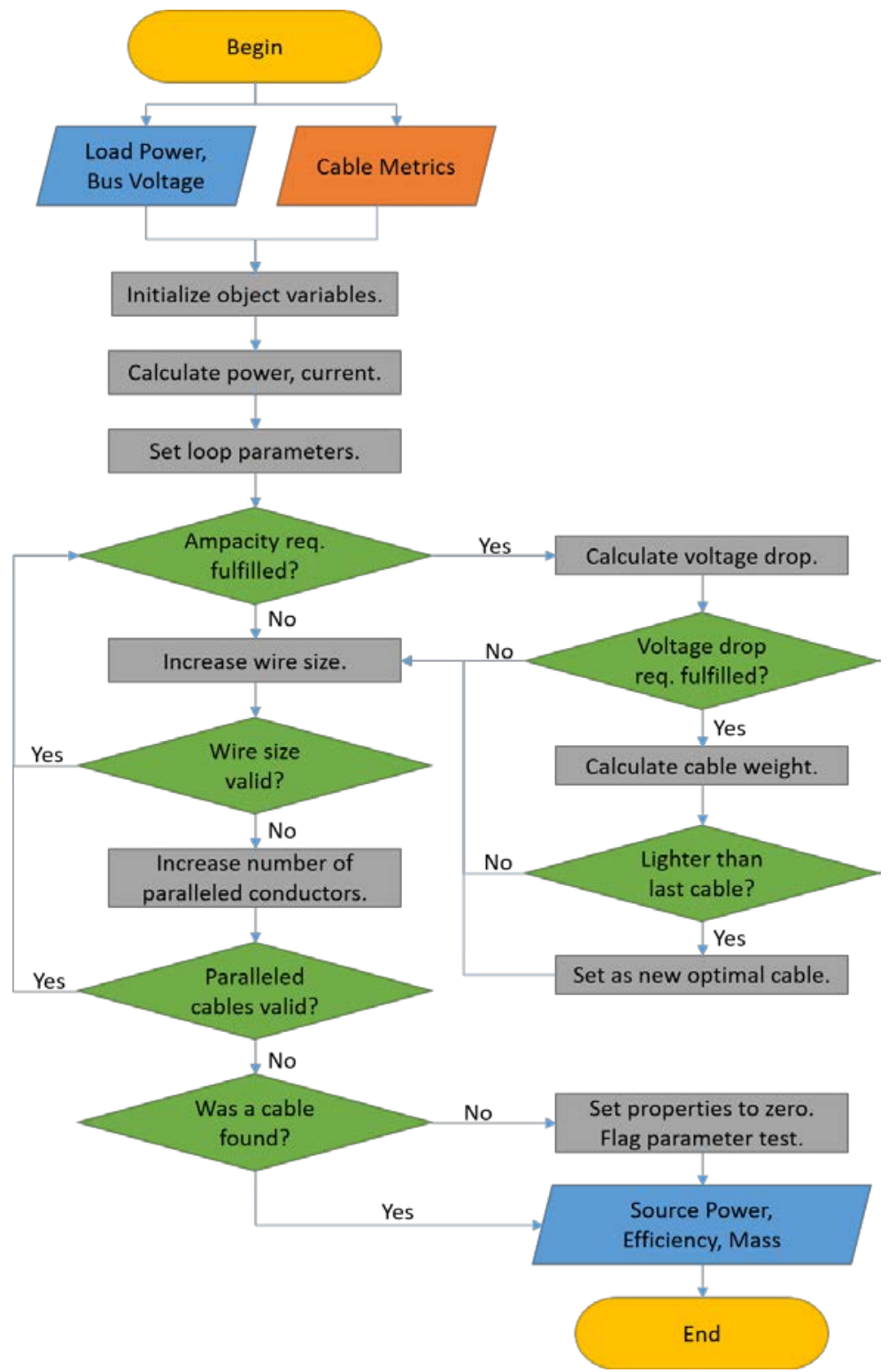

Figure 3: Cable Selection Process Flow Diagram

\section{Switchgear}

To date, limited information is available based on the size and efficiency characteristics of AC and DC switchgear for high power aircraft application. ${ }^{7,8}$ Ref. 8 estimated the real power density of AC and DC switchgear at $350 \mathrm{~kW} / \mathrm{kg}$ and $200 \mathrm{~kW} / \mathrm{kg}$ respectively. These values will be treated as the nominal $\mathrm{kVA} / \mathrm{kg}$ power densities for the purpose of this paper with assumed efficiencies of $99.5 \%$. For the case of the generator, the AC switchgear will use an apparent power density KPP (350 kVA/kg) to provide a fair comparison with the DC switchgear. The impact of the power density assumptions will be assessed through a sensitivity sweep as well.

To make a fair comparison between the AC and DC circuit breakers, the DC switchgear must account for losses on both lines. Two DC circuit breakers, one on each line, can be considered the equivalent of two series circuit breakers on a single-line. Therefore, the efficiency of a set of dc circuit breakers is estimated and corrected for series configuration such that

$$
\eta_{\text {corrected }}=2 \eta_{\text {baseline }}-1 .
$$

American Institute of Aeronautics and Astronautics 


\section{E. Thermal System}

Similar to switchgear, limited information is available based on the sizing of thermal systems for high power aircraft application. Ref. 5 sized the thermal system at $0.38 \mathrm{~kW} / \mathrm{kg}$ based on the loss extracted from the power train. This KPP metric will be utilized as a baseline value for the existing thermal system.

\section{STARC-ABL Architecture and Trade Assessment}

The STARC-ABL Vehicle, as shown in Figure 4, is a single-aisle aircraft utilizing two turbofans and a 2.61 MW electrically powered aft thruster. A notional power train for this vehicle, also shown in Figure 4, was originally described and studied in Ref. 5. This power train converts AC power from two turbofan-coupled generators to DC power via rectifiers, transmits the power across a DC transmission (cable) network, and then inverts the power back to AC to drive the aft propulsor motor. The simplicity of the vehicle power train architecture (AC-DC-AC) serves as a good candidate for analysis and initial testing of the proposed power system architecture sizing and analysis framework.

To build on the work, ${ }^{5}$ a modified power train is proposed such that the DC transmission network and circuit breakers are replaced with an AC transmission network and circuit breakers, as shown in Figure 5. It has been noted in Ref. 9 that AC transmission networks have 33\% less loss over DC transmission networks with the same copper utilization; this however is without considering skin- and proximity- effects. Traditional AC circuit breakers are also known to have a mass advantage over similarly rated DC circuit breakers, which is advantageous. Therefore, it has been deemed worthwhile to examine if there may be mass and/or efficiency advantages to an AC transmission system over that of a DC System for the STARC-ABL Vehicle power train.

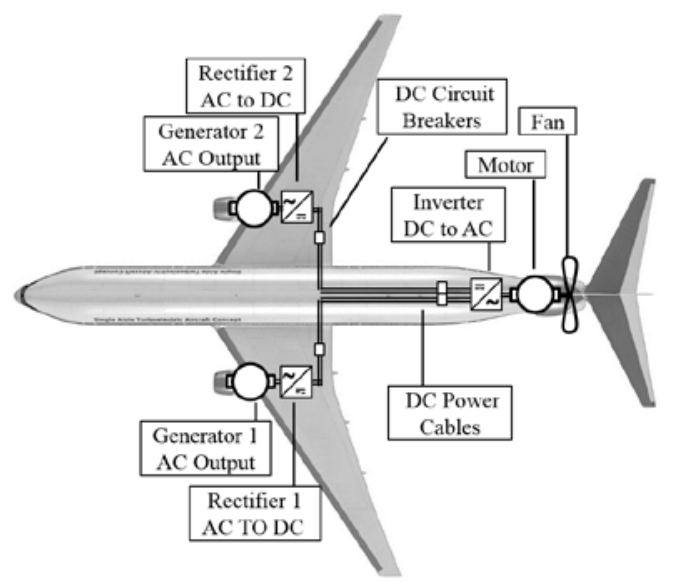

Figure 4: STARC-ABL DC Power System Architecture

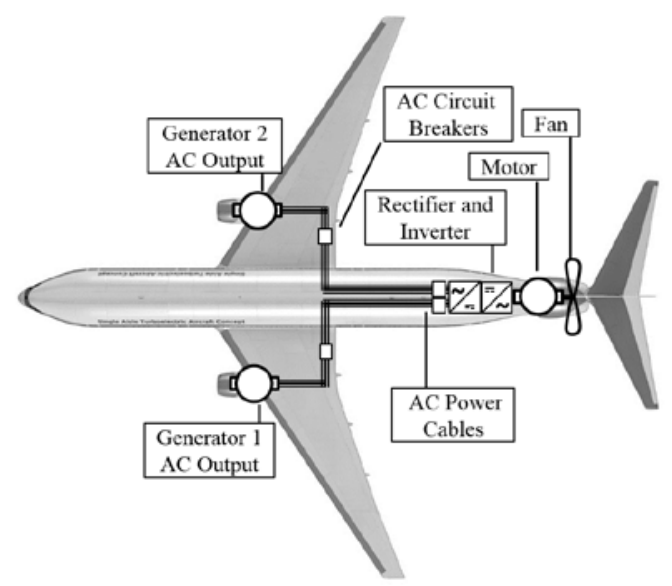

Figure 5: STARC-ABL AC Power System Architecture

\section{Trade Results}

The proposed coding framework was implemented within MATLAB. The AC and DC transmission architectures were traded to preliminarily assess the performance benefits of one versus the other for a standard AC-DC-AC power train for the STARC-ABL Vehicle. The architectures were traded based on the nominal KPPs described previously for a bus voltage ranging from $600 \mathrm{~V}$ to $2 \mathrm{kV}$, along with a parametric analysis to determine the system sensitivity relative to the switchgear and thermal mass. For total trade comparison, the results from these trade studies are presented in terms of system-wide efficiency, mass, and loss.

\section{A. Nominal Trade with Bus Voltage Sweep}

The first trade study was based upon a $600 \mathrm{~V}$ to $2 \mathrm{kV}$ sweep across three power system topologies: DC and 3-phase AC at $400 \mathrm{~Hz}$ and $800 \mathrm{~Hz}$. The purpose of this study was to apply the data in the cable class to examine the systemwide impact of voltage and frequency on the skin- and proximity-effects. For this test, the parallel cable limit was set to 4 parallel cables and the voltage drop tolerance equal to three percent.

As shown in Figure 6, the results of the bus voltage sweep indicate that it is advantageous to increase bus voltage for systems which operate at frequencies less than $800 \mathrm{~Hz}$ in the voltage range $600 \mathrm{~V}$ to $2 \mathrm{kV}$. The System Mass plot 
indicates that, as voltage increases, lighter cables are chosen which reduces the total mass of the aircraft, however, this plot was created by sweeping only up to $2 \mathrm{kV}$. Past $2 \mathrm{kV}$, cables must have an increased amount of insulator material which adds to the weight of the system; cable metrics, such as high-voltage tolerance, may be considered in another study comprising of a higher fidelity cable module. Similarly, to fully gauge the system-wide effects of voltage and frequency, it is also necessary to consider the effects on the efficiency and sizing of machines and switchgear. Such analysis would require expansion on the machine and switchgear classes.

Another observation from Figure 6 includes the benefit of utilizing an AC transmission topology over DC transmission topology. This benefit is evident in the System Loss and System Efficiency plots where the DC transmission topology resulted in approximately $736 \mathrm{~kW}$ loss at $78 \%$ efficiency, whereas the AC transmission topology resulted in approximately $640 \mathrm{~kW}$ loss at $80 \%$ efficiency. Changing the power train to AC would reduce the thermal loss near 13\%. It can be observed that the skin- and proximity-effect have large impact on the overall system performance. Though the AC transmission topology demonstrates greater efficiency and less loss, the DC topology may be superior to AC systems operating at frequencies greater than $800 \mathrm{~Hz}$ due to cable loss mechanisms in the AC architecture that impact system weight and efficiency.
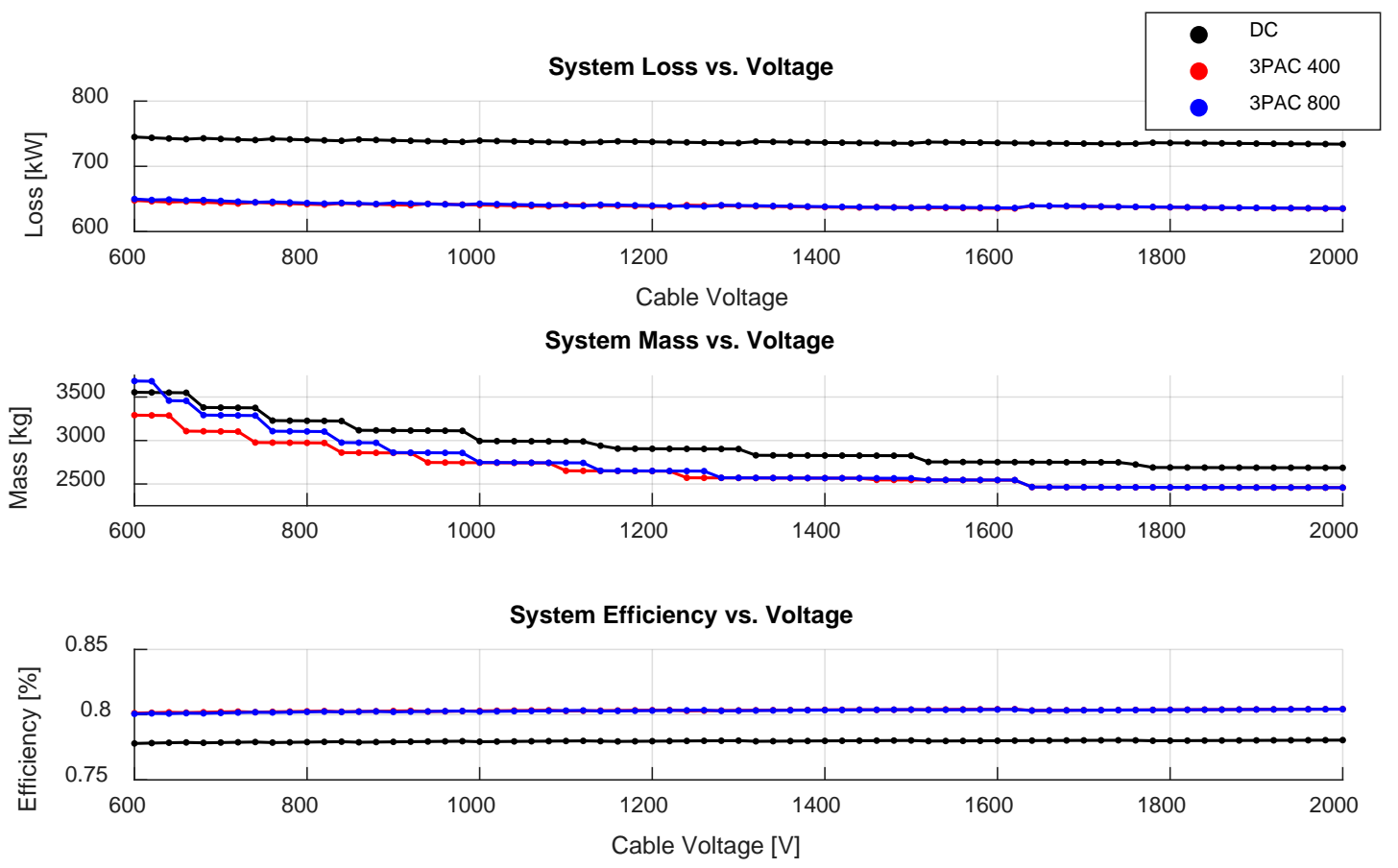

Figure 6: Bus Voltage Sweep Results

The plots shown in Figure 7 and Figure 8 also display a sweep of the bus voltage, but, rather than studying different power system topologies, the plots show the $400 \mathrm{~Hz}$ and $800 \mathrm{~Hz}$ AC system topologies with one, two, and four paralleled transmission cables. It is observable that system mass is most effected by paralleling transmission cables. Perhaps a hidden piece of information that may be derived from these plots is that the paralleling of cables permits power system designs with lower voltages. This is most observable in the System Mass plots where the single cable system (black line) shows no compatible cable found until nearly $1.3 \mathrm{kV}$ in the $400 \mathrm{~Hz}$ transmission system.

American Institute of Aeronautics and Astronautics 

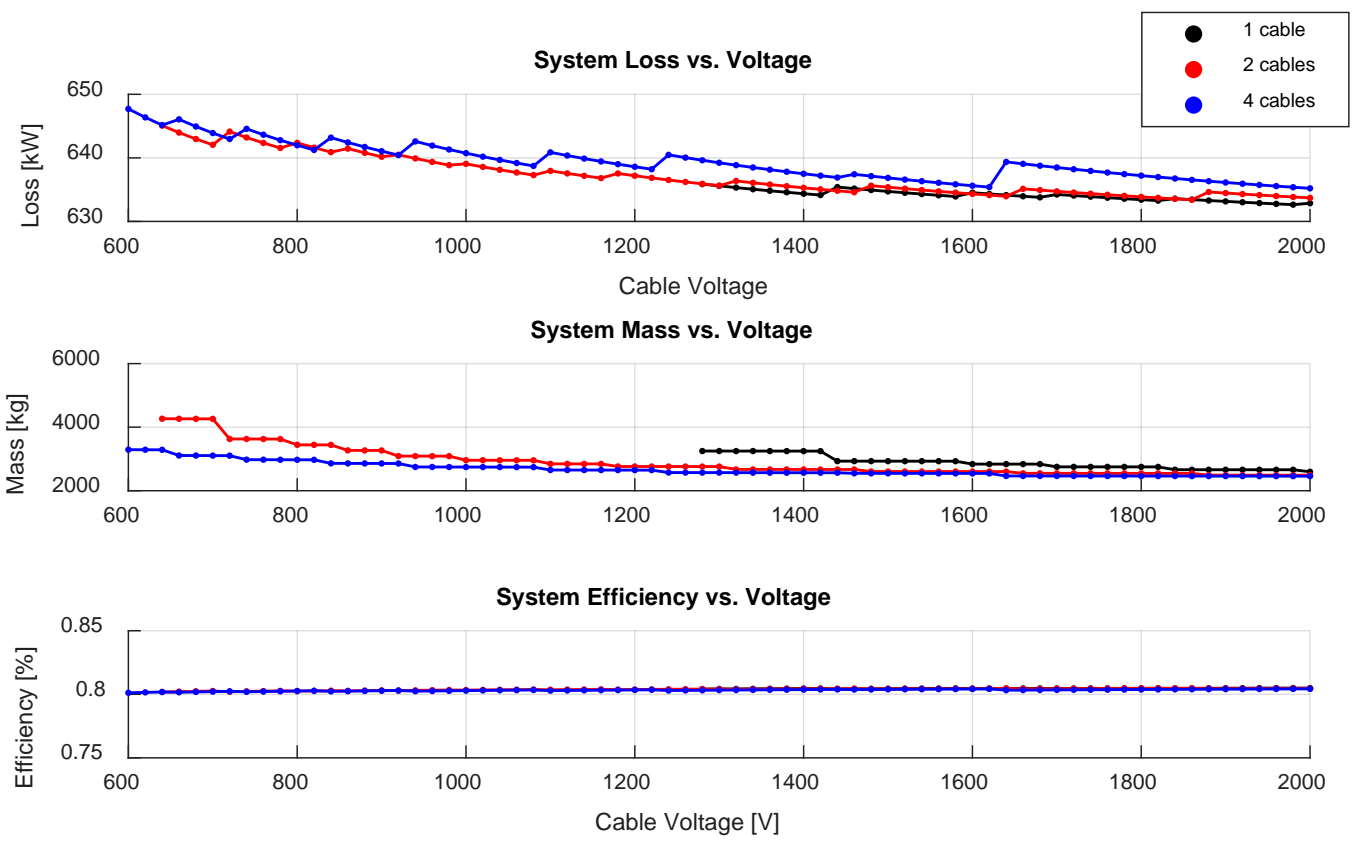

Figure 7. $400 \mathrm{~Hz}$ System Sweep of Paralleled Cables and Bus Voltage
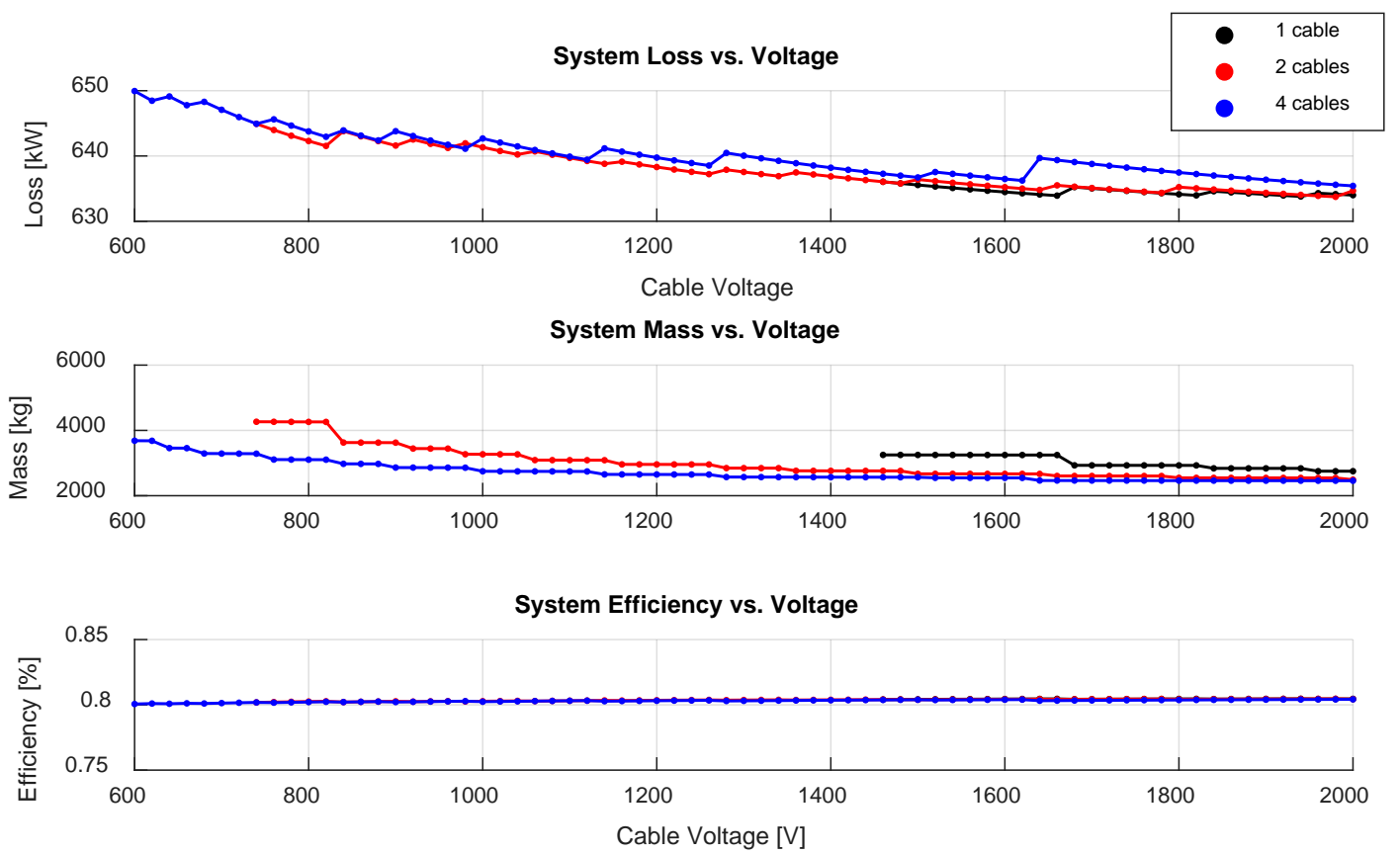

Figure 8: $800 \mathrm{~Hz}$ System Sweep of Paralleled Cables and Bus Voltage

\section{B. Switchgear Sensitivity Analysis}

The second trade study was based upon a sweep of the switchgear power density from $50 \mathrm{~kW} / \mathrm{kg}$ to $500 \mathrm{~kW} / \mathrm{kg}$. For this test, the bus voltage, parallel cable limit, and voltage drop tolerances were set to $1200 \mathrm{~V}$, four parallel cables, and three percent respectively. The purpose of this trade study was to examine the total system sensitivity from sweeping a single component parameter: switchgear power density. In this study the component power density is used to calculate component mass and, therefore, has no effect on the system loss or efficiency. As observed in the System 
Mass plot in Figure 9, switchgear power density has a moderate impact on the total system mass for both the AC and DC systems. The DC system appears less sensitive to switchgear power density improvements than the AC systems, although all three system types appear to be past the knee of sensitivity curves. Metrics such as this can be used to further analyze the tradeoffs when considering AC systems versus DC systems.

The switchgear sensitivity analysis is an example of how component-level impacts can be measured to select where greater component-level focus should be initiated. Also, this type of analysis is not only limited to individual components. For example, like the voltage/frequency sweep performed previously, the system operating parameters also effect the total system performance.
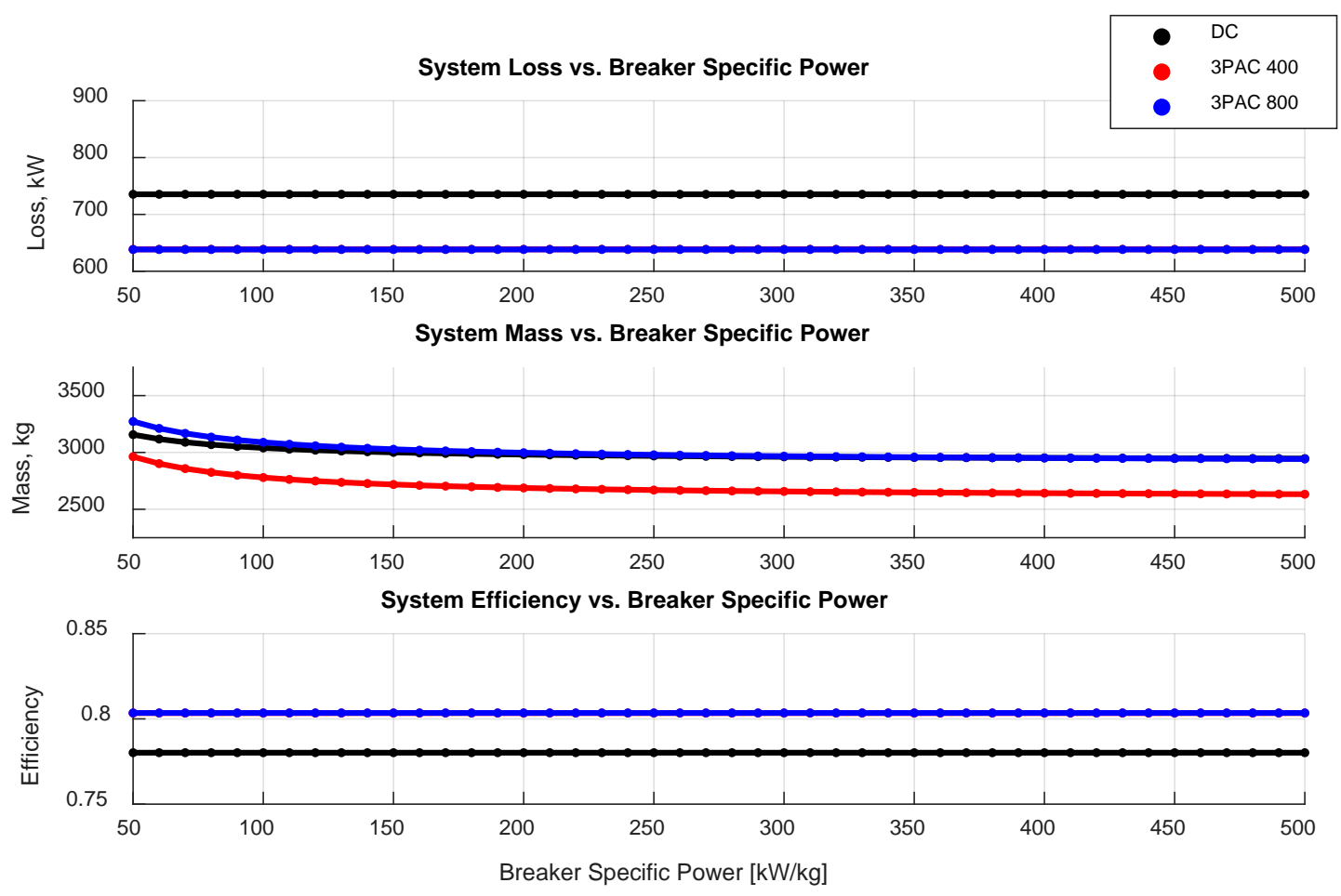

Figure 9: Switchgear Sensitivity Sweep Results

\section{Thermal Mass Sensitivity Analysis}

The third trade study was based upon a sweep of the total system thermal power density from $0.05 \mathrm{~kW} / \mathrm{kg}$ to 0.5 $\mathrm{kW} / \mathrm{kg}$. Like the switchgear power density sweep, the bus voltage, parallel cable limit, and voltage drop tolerances were set to $1200 \mathrm{~V}$, four cables, and three percent respectively. The purpose of this study was to provide insight on system weight in relation to varying the thermal system power density. Again, in this study, the thermal power density is used to calculate total thermal mass which has no effect on the loss or efficiency. As observed in Figure 10, the System Mass plot indicates that the thermal specific power is a critical parameter in reducing power system mass. The systems appear to be highly sensitive to thermal system specific power improvements up until approximately 0.2 to $0.25 \mathrm{~kW} / \mathrm{kg}$. 

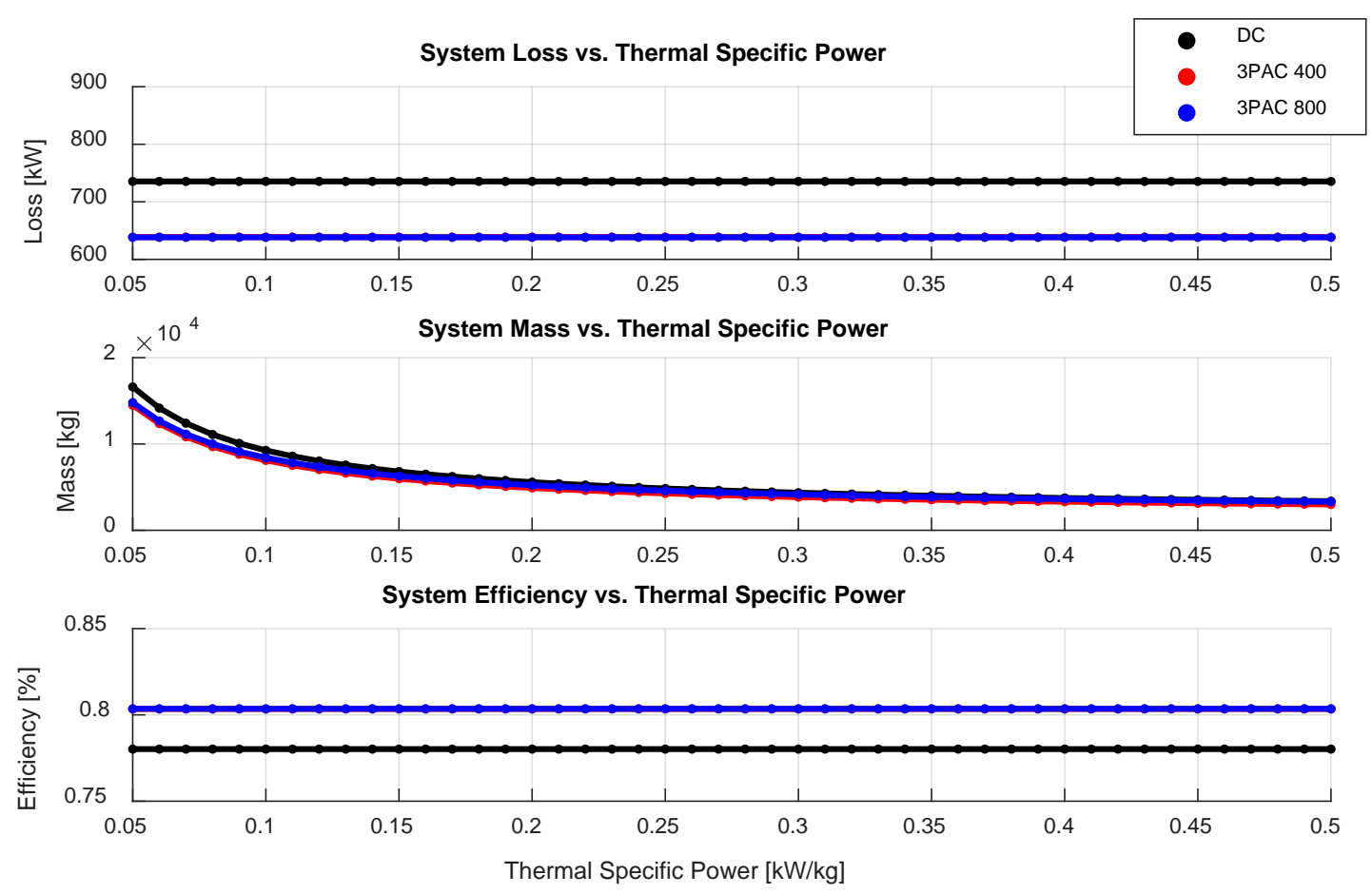

Figure 10: Thermal Mass Sweep Results

\section{Conclusion and Future Work}

To increase aircraft efficiency, reduce emissions, and reduce dependency on fossil fuels, NASA has identified and begun research in electrifying aircraft. The work in this paper described an approach to sizing the power system architecture of an electrified aircraft. A tool was developed in the MATLAB ${ }^{\circledR}$ environment which accepted the speed and torque requirements required by the motors and determined the size of the power system components as well as the weight, thermal impact, and losses in the system from the motor to the source.

Three trade studies were performed using this tool on a STARC-ABL aircraft configuration to verify that the power sizing framework was capable of satisfying the benefits stated in Section II. The results of these trade studies, and others like them, can be used to select whether an aircraft is to be hybrid- or turbo-electric and/or whether the power system is to be AC or DC. It should be noted however, that effects such as EMI and equipment location limitations should be taken into consideration when choosing the proper system for the application. In the case of the results presented in this paper, higher fidelity of the component modules would present further insight on the benefits of different architectures. This can be obtained by scaling component power densities based on size, power demand, and frequency. Further investigation may also be required in distributed propulsion systems where various motor sizes, branch circuits, and feeders are implemented throughout the system. The cable module can be refined to add relevant data based on different cable materials (conductors and insulation), geometries, grounding, and higher frequencies as data becomes available. Power system components, such as batteries or other energy storage elements, can also be included in the power sizing framework to increase the breadth of which aircraft may be evaluated.

Another application of such power sizing framework may be in space power systems. Due to the modular nature of the power sizing framework, space power components, such as power converters or thrusters, can be modeled with their respective KPPs and implemented in a full space power system analysis. 


\section{References}

${ }^{1}$ Ashcraft, S.W., Padron, A.S., Pascioni, K.A, Stout Jr., G.W., and Huff, D.L., "Review of Propulsion Technologies for N+3 Subsonic Vehicle Concepts,” NASA TM 2011-217239, October, 2011.

${ }^{2}$ Hathaway, M.D., Del Rosario, R., and Madavan, N.K., "NASA Fixed Wing Project Propulsion Research and Technology Development Activities to Reduce Thrust Specific Energy Consumption,” NASA TM 2013-216548, July 2013.

${ }^{3}$ Antcliff, K.R., Guynn, M.D., Marien, T.V., Wells, D.P.., Schneider, S.J., and Tong, M.T., "Mission Analysis and Aircraft Sizing of Hybrid-Electric Regional Aircraft," AIAA 2016-1028, AIAA SciTech, 54 ${ }^{\text {th }}$ AIAA Aerospace Sciences Meeting, San Diego, CA, January 4-8, 2016.

${ }^{4}$ Welstead, J.R., and Felder, J.L., "Concept Design of a Single-Aisle Turboelectric Commercial Transport with Fuselage Boundary Layer Ingestion,” AIAA 2016-1027, AIAA SciTech, $54^{\text {th }}$ AIAA Aerospace Sciences Meeting, San Diego, CA, January 4-8, 2016.

${ }^{5}$ Ralph Jansen, Cheryl Bowman, and Amy Jankovsky. "Sizing Power Components of an Electrically Driven Tail Cone Thruster and a Range Extender", 16th AIAA Aviation Technology, Integration, and Operations Conference, AIAA AVIATION Forum, (AIAA 2016-3766)

${ }^{6}$ Conductor Resistances and Ampacities at High Frequencies. Insulated Power Cable Engineers Association (IPCEA). Publication P-43-457. April, 1961.

${ }^{7}$ National Academies of Sciences, Engineering, and Medicine. 2016. Commercial Aircraft Propulsion and Energy Systems Research: Reducing Global Carbon Emissions. Washington, DC: The National Academies Press. https://doi.org/10.17226/23490.

${ }^{8}$ Architecture, Voltage, and Components for a Turboelectric Distributed Propulsion Electric Grid. Michael J. Armstrong, Mark Blackwelder, Andrew Bollan, Christine Ross, Angela Campbell, Catherine Jones, and Patrick Norman. s.l. : NASA, 2015. NASA/CR-2015-218440.

${ }^{9}$ Davey, K.R., and Hebner, R.E., "Power Grid for a Naval Electric Ship - AC Versus DC", Texas Scholar Works, University of Texas Libraries, The University of Texas at Austin, Austin, Texas, (unpublished).

American Institute of Aeronautics and Astronautics 